\title{
Electron-Microscopic Study of Silver Iodide as Contact or Sublimation Nuclei ${ }^{1}$
}

\author{
FARN P. PARUngo \\ Environmental Research Laboratories, NOAA, Boulder, Colo. 80302 \\ (Manuscript received 18 September 1972, in revised form 4 December 1972)

\section{ABSTRACT}

\begin{abstract}
Experiments of ice nucleation by silver iodide were conducted in a cold chamber at various temperatures. The seeded ice crystals were replicated and an examination of the position of AgI nuclei in individual ice crystals was made using an electron microscope. The mechanism of ice nucleation is discussed.
\end{abstract}

\section{Introduction}

In cloud seeding experiments silver iodide is widely used as an ice nucleation agent, yet the mechanism by which it acts as a nucleating agent is still not well understood. There are four different roles which ice nuclei can play to initiate the ice phase (Gokhale, 1969): 1) at ice supersaturation AgI can act as a sublimation nucleus by converting water vapor to ice; 2) at water supersaturation AgI can serve as a freezing nucleus by condensation of water on its surface, followed by crystallization; 3) it is embedded in a droplet acting as bulk freezing nucleus; and 4) it can play a role as a contact nucleus by the crystallization process upon contact of an AgI particle with the supercooled droplet. The relative importance of these mechanisms at different conditions have been studied by Cwilong (1949), Schaefer (1954), Birstein (1955), Mossop (1956), Edwards and Evans (1960), and Balabanova and Zhigalovskaya (1962).

Silver iodide is a hydrophobic substance. It can serve as a condensation-freezing nucleus if it contains hydrophilic impurities, such as sodium iodide. Also, silver iodide can act as a bulk-freezing nucleus if it is prewetted. When pure and dry AgI aerosols are used as ice nuclei, the major mechanism should be considered as either contact or sublimation nucleation. Weickmann et al. (1970) suggested that crystals with a center circle could be traced back to their origin from a frozen droplet and that $\mathrm{AgI}$ particles acted as contact nuclei rather than sublimation nuclei even at temperatures as low as $-17 \mathrm{C}$. To add credence to the understanding of contact nucleation, it is the purpose of this study to search for evidence of coalescence between an AgI particle and a supercooled droplet followed by initiation of freezing and subsequent ice-crystal growth.

If an AgI particle acts as a contact nucleus, it collides with a supercooled drop and initiates ice-

${ }^{1}$ Part of this study was presented at the Third Conference on Weather Modification at Rapid City, S. D., on 16 June 1972. crystal growth (Gokhale and Lewinter, 1971). Thus, an AgI particle should be at the boundary of the drop and would be found anywhere in the projected-center frozen droplet in the replica. If condensation-freezing or bulk-freezing nucleation is the case, the nucleus could also be located anywhere within the droplet. However, in this case, the AgI particle could dissolve either partly or completely in the embedded droplet, depending on the size of the particle, to yield an AgI solution. When such an ice crystal sublimes during the process of replication, the initial droplet would leave a dark center circle of $\mathrm{AgI}$ residue in the replica. If $\mathrm{AgI}$ serves as a sublimation nucleus, it should be at the $c$ axis of the nucleated ice crystal and should be found at the center of the symmetry of the ice crystal. Therefore, by examination of an individual AgI nucleus in relation to an individual ice crystal, one may clarify their mode of origin. To accomplish this, it is necessary to study ice crystal replicas with an electron microscope.

\section{Experiment}

Silver iodide aerosol was produced by electrically heating an AgI coated nichrome wire (Sax, 1970) and was stored in an aluminized Mylar bag. The concentration of the aerosol was approximately 20,000 liter ${ }^{-1}$. Their size distribution was obtained from an electron microscopic analysis of thermal precipitator samples. Approximately $90 \%$ of all the particles were less than $0.1 \mu \mathrm{m}$ and $50 \%$ were less than $0.01 \mu \mathrm{m}$ in diameter. Seeding experiments were carried out in a cold chamber whose temperature could be controlled within $\pm 2 \mathrm{C}$. A cloud was formed by introduction of moisture into the chamber from an atomizer. When the condition in the cold chamber had stabilized, silver iodide aerosol which was freshly prepared in the bag was introduced into the chamber to produce ice crystals. Moisture was supplied continuously during the experiment to keep it in water supersaturation except in one case which was specified. 


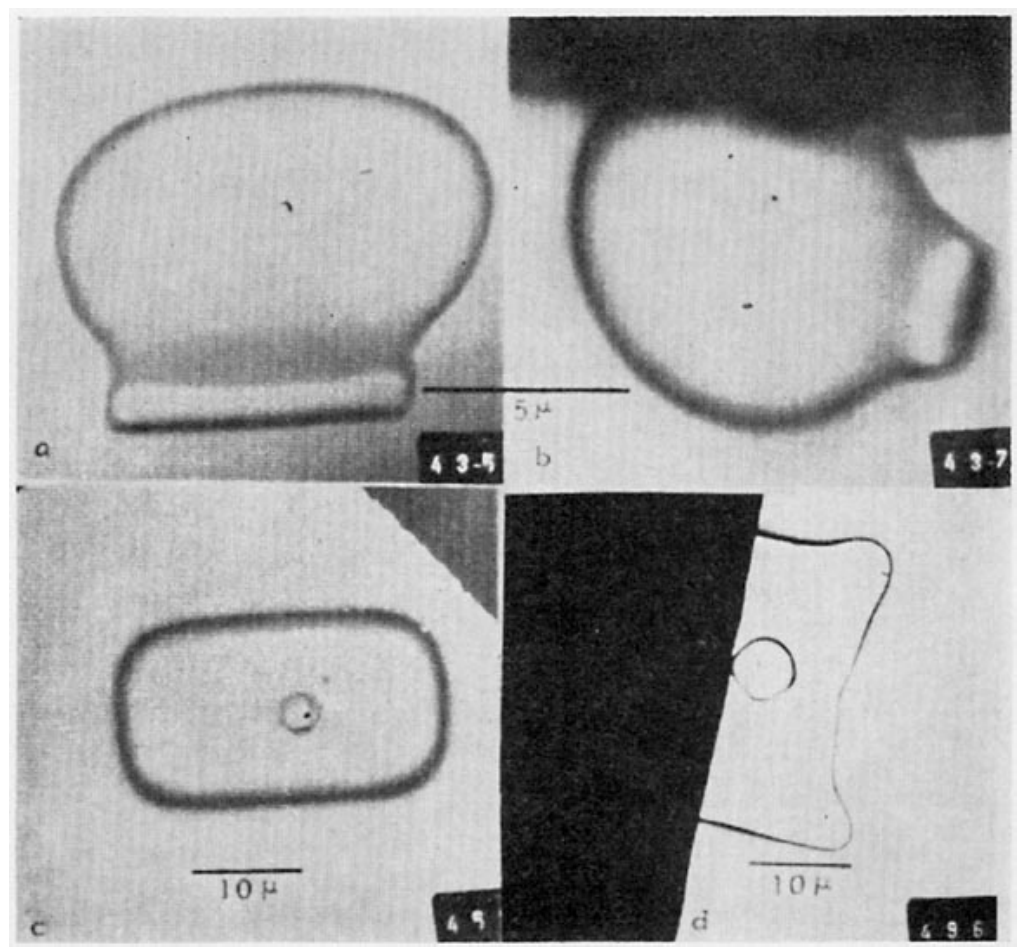

FIG. 1. Silver iodide seeded ice crystals obtained at $-8 \mathrm{C}$ : (a) and (b) frozen drops; (c) and (d) columns.

In order to obtain an ice-crystal replica which can illustrate its detailed structure and also be thin enough to allow passage of an electron microscope beam, a technique developed by Schaefer ${ }^{2}$ was adopted as follows: The sampling screens (200 mesh) were coated with $1 \%$ collodion solution in amylacetate and set on a slide. The slide with the screens on it was then dipped in a $0.25 \%$ Formvar solution in ethylene dichloride and allowed to dry. This doubly coated slide was placed on the bottom of the cold chamber to receive the AgI seeded snow crystals. A 50-ml beaker with chloroformwetted filter paper at the bottom was then cooled below $0 \mathrm{C}$ and used to cover the sampling slide for $30 \mathrm{sec}$. Thus, a cold chloroform vapor was generated in the beaker to dissolve the top layer of Formvar

Table 1. Percentage of ice crystals at various temperatures.

\begin{tabular}{lccccccc}
\hline \hline & \multicolumn{7}{c}{ Temperature $\pm 2 \mathrm{C}$} \\
\multicolumn{1}{c}{$\begin{array}{c}\text { Type of crystals } \\
\quad \text { examined }\end{array}$} & $\mathbf{4 0}$ & $\mathbf{1 1 2}$ & $\mathbf{5 0}$ & $\mathbf{5 0}$ & $\mathbf{1 5 0}$ & 200 & 64 \\
\hline $\begin{array}{l}\text { Plate with a nucleus in } \\
\text { the center circle }\end{array}$ & - & 70 & 80 & 90 & 30 & 20 \\
$\begin{array}{l}\text { Plate with a center } \\
\text { nucleus }\end{array}$ & - & - & - & 10 & 15 & 70 \\
$\begin{array}{l}\text { Solid column } \\
\text { Hollowed column }\end{array}$ & $\mathbf{5 0}$ & 20 & 20 & - & 10 & 10 \\
$\begin{array}{l}\text { Bullet } \\
\text { Needle }\end{array}$ & $\mathbf{3 0}$ & $\mathbf{1 0}$ & - & & 30 & - \\
& $\mathbf{2 0}$ & - & - & - & 10 & - \\
\hline
\end{tabular}

* At ice supersaturation.

2 Private communication, 1967. on the screens, causing the Formvar to migrate over the ice crystals and replicate them on the supporting collodion film. Precautions which were taken to prevent any possible movement of an AgI nucleus during the replication are as follows: The slide with replicas remained in the cold chamber for at least $4 \mathrm{hr}$ to allow the completion of ice-crystal sublimation; and before the slide was removed from the cold chamber, a warm slide was used to cover the replicated slide in order to avoid the condensation of moisture on the replicas and thus possibly move the nuclei. After warming up to room temperature, the screens were removed from the slide and were ready for examination by the electron microscope.

\section{Results and discussion}

The experimental results are summarized in Table 1. For each experimental temperature, 10 sampling screens were used to collect the AgI-seeded ice crystals. The replication method yielded a fine and detailed structure for a thin or small crystal. However, a large column whose thickness could retard the flow of Formvar solution over the whole crystal usually produced a poor replica. The crystal habit of the seeded ice crystals generally followed Nakaya's diagram. At temperatures above $-10 \mathrm{C}$ there were frozen drops, needles and columns. Four selected electron micrographs are shown in Fig. 1: (a) and (b) are frozen drops with an enclosed particle which subsequently grew to an 

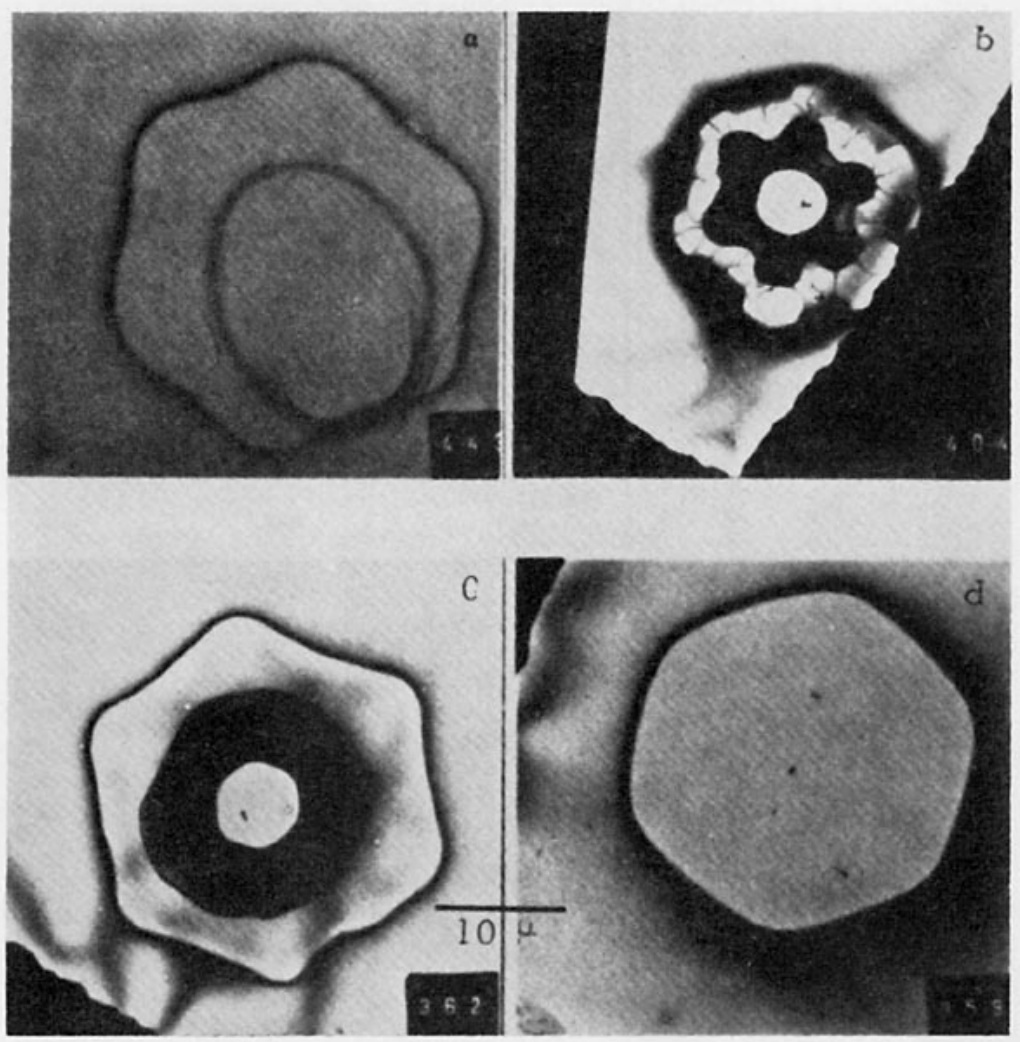

Fig. 2. Ice crystals obtained at (a) $-12 \mathrm{C}$, (b) $-16 \mathrm{C}$, (c) $-20 \mathrm{C}$, (d) $-20 \mathrm{C}$.

ice crystal, while (c) and (d) are column ice crystals with a center circle containing a particle. It appears that the crystallization origin depends on the collision and coalescence of a supercooled water drop and an AgI nucleus. When the temperature was between -10 and $-20 \mathrm{C}$, the majority of ice crystals observed were hexagonal plates as shown in Fig. 2: (a) at $-12 \mathrm{C}$, (b) at $-16 \mathrm{C},(\mathrm{c})$ at $-20 \mathrm{C}$. In each of these crystals, there was a center circle with a particle in it. It again shows that contact nucleation is the dominant mechanism. However, at $-20 \mathrm{C}, 10 \%$ of the observed crystals did not have a circle but possessed a nucleus at their center of symmetry as shown in Fig. 2(d). This gives the impression that the AgI particle acted as a sublimation nucleus. Indeed, when an experiment was carried out at -16 to $-20 \mathrm{C}$, at ice supersaturation produced by discontinuing the supply of moisture after excess seeding by AgI aerosol, $70 \%$ of the ice crystals received did not possess a center drop as shown in Fig. 3. The AgI nucleus was at the center of the hexagonal symmetry indicating the role of sublimation nucleation. However, when the experiment was attempted at a temperature between -10 and $-14 \mathrm{C}$, no ice crystals were obtained after the moisture supply was cut off. This suggests that sublimation nucleation was not active at temperatures $>-14 \mathrm{C}$.

Ice crystals formed at temperatures of -24 to $-26 \mathrm{C}$ are shown in Fig. 4: (a) and (b) are examples of hex- agonal plates with a center circle. They contribute approximately $30 \%$ of the total ice crystals observed; the nucleus is not at the center of the crystal but in the boundary of the projected center frozen drop. Fig. 4(c) shows a solid column crystal with a circle along its $c$ axis and with an AgI particle in the circle $(10 \%)$. Crystals shown in Figs. 4(a)-(c) can be identified as contact ice nucleation origin. Fig. $4(d)$ is a hexagonal plate with a nucleus at the center of the crystal symmetry but without a center circle (15\%). It may trace back to sublimation mucleation origin. Figs. 4(e) and 4(f) show two hollowed columns (30\%). One can observe that they contain a frozen drop in the center of the column and contact nucleation plays a role in nucleation of the ice phase. Figs. $4(\mathrm{~g})$ and $4(\mathrm{~h})$

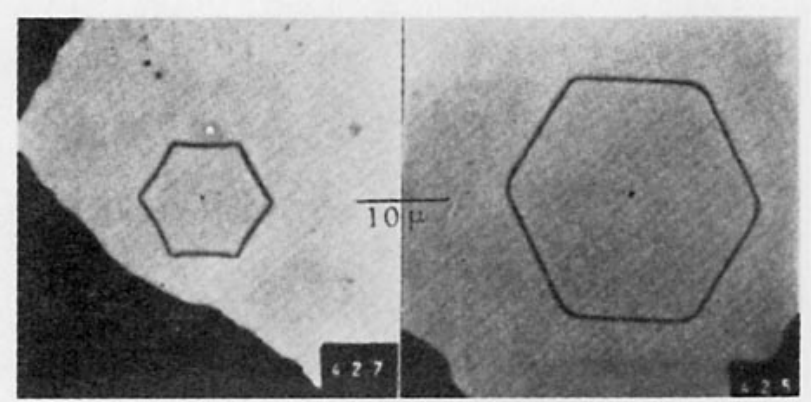

FIG. 3. Ice crystals obtained at $-18 \mathrm{C}$ at ice supersaturation. 


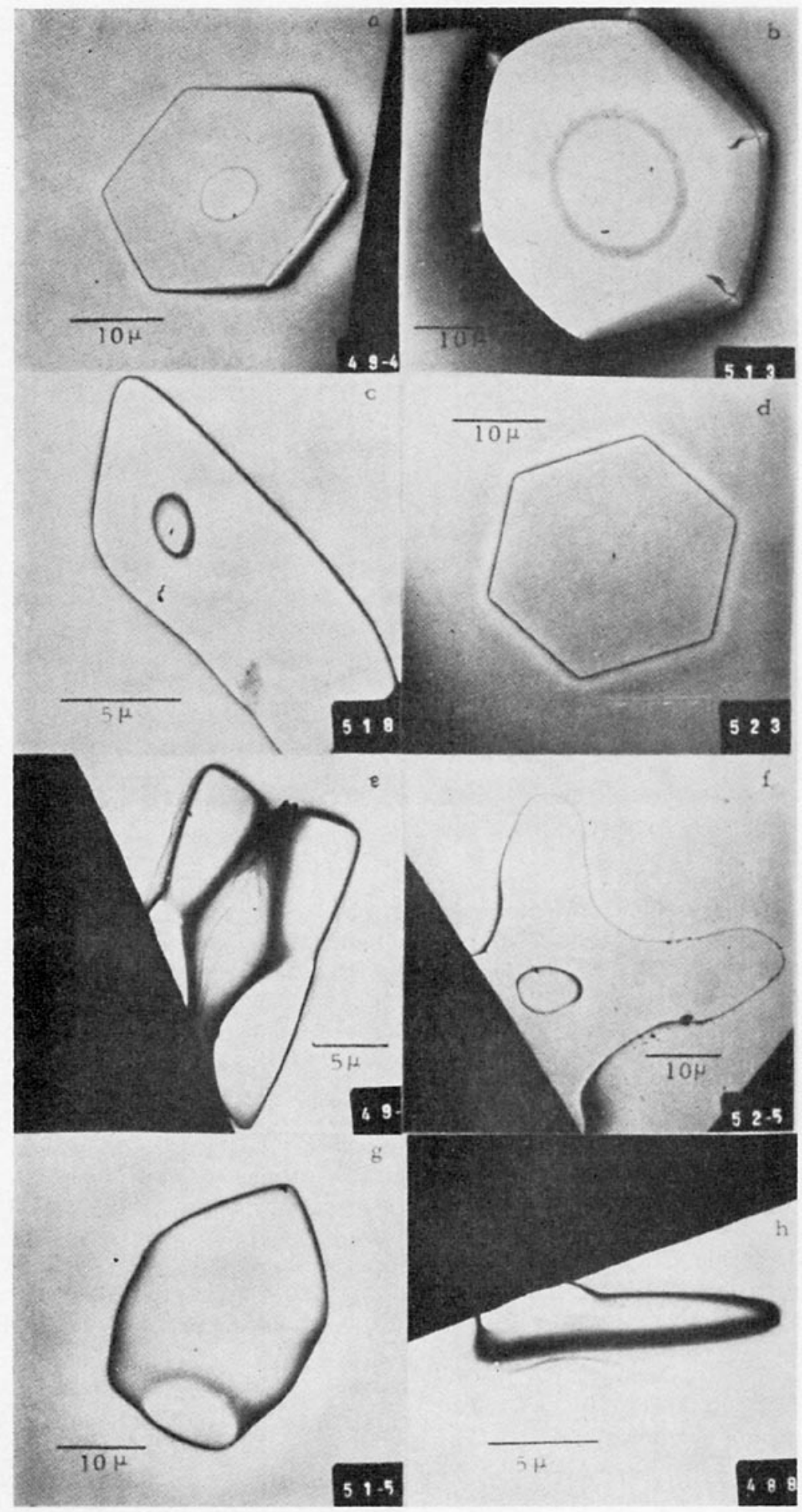

FIG. 4. Ice crystals obtained at $-24 \mathrm{C}$. See text for explanation.

are bullet crystals. The oval-shaped shadow at the end of the crystal might be the imprint of a droplet which may have been the initiate of the crystal growth. However, a particle found at the tip of the bullet shown in Fig. $4(\mathrm{~g})$ leads one to believe that the crystal formed from the tip (10\%). When this crystal fell on the sampling film, the tip of the bullet lay over the film for a distance of half of the bullet width. It would 


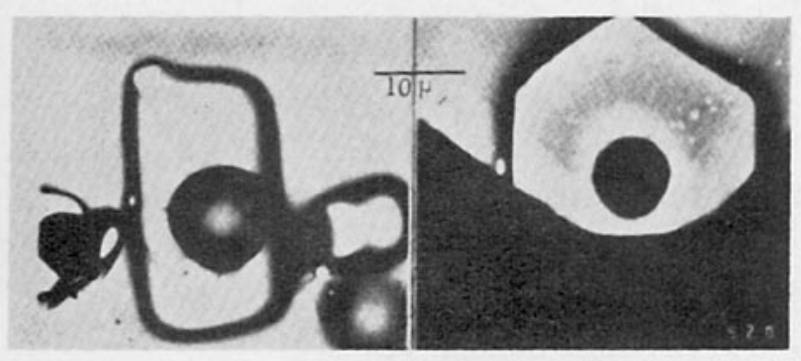

FIG. 5. Ice crystals with clouded circles: (a) obtained at $-8 \mathrm{C}$, (b) at $-24 \mathrm{C}$.

be difficult to produce a detailed replica of this portion. This may be the reason why no frozen drops can be observed at the tip.

In very rare cases, ice crystals possessed a clouded circle as shown in Fig. 5. It appeared that the original droplet dissolved either an AgI nucleus or other impurity before the crystallization to leave such an opacity circle. Therefore, the nucleus might be considered as condensation-freezing nucleus.

\section{Conclusion}

Experiments of ice nucleation by silver iodide were conducted in a cold chamber at various temperatures. An electron microscope was used to examine the ice crystal replicas. When the temperatures were above $-20 \mathrm{C}$ and at water supersaturations, the majority of the ice crystals possessed a center circle containing an AgI particle. It was evident that contact nucleation was a dominant mechanism. However, when the temperature was lower than $-16 \mathrm{C}$ and the humidity decreased to ice supersaturation, a large portion of the ice crystals did not show a center circle and the AgI nucleus was always found at the crystal's center of symmetry. This indicates that sublimation nucleation took place. Based upon the electron-microscopic study of the seeded ice crystal replicas, one may distinguish the modes of origin of ice nucleation.

Acknowledgments. This study was directed by Dr. Helmut Weickmann. The author would like to express her appreciation to Dr. Jan Rosinski of NCAR for the use of NCAR's electron microscope and Mr. Clarence Nagamoto for his assistance on electron-microscopic techniques.

\section{REFERENCES}

Balabanova, V. N., and T. N. Zhigalovskaya, 1962: On the use of silver iodide in the crystallization of supercooled water. Ivz. Akad. Nauk SSSR, Ser. Geofiz., 904-906.

Birstein, S. J., 1955: The role of absorption in heterogeneous nucleation. $J$. Meteor., 12, 324-331.

Cwilong, B. M., 1949: Sublimation in out-door air and seeded sublimation. Nature, 163, 727-728.

Edwards, G. R., and L. F. Evans, 1960: Ice nucleation by silver iodide: Freezing vs sublimation. $J$. Meteor., 17, 627-634.

Gokhale, N. R., 1969: The mechanics of ice nucleation induced by AgI particles in a supercooled cloud. Proc. 7 th Intern. Conf. Condensation and Ice Nuclei, Prague and Vienna, Publ. House Czech. Acad. Sci., 200-205.

- , and O. Lewinter, 1971: Microcinematographic studies of contact nucleation. J. Appl. Meteor., 10, 469-473.

Mossop, S. C., 1956: Sublimation nuclei. Proc. Phys. Soc., B69, 161-164.

Sax, R. I., 1970: Drop freezing by Brownian contact nucleation. Ph.D. thesis, University of London.

Schaefer, V. J., 1954: Silver and lead iodide as ice crystal nuclei. $J$. Meteor., 11, 417-419.

Weickmann, H. K., U. Katz and R. Steele, 1970: AgI--Sublimation or contact nucleus? Preprints. Second Conf. Wealher Modification, Santa Barbara, Calif., Amer. Meteor. Soc., 332-336. 